\title{
Induction of Adult-type Nicotinic Acetylcholine Receptor Gene Expression in Noninnervated Regenerating Muscle
}

\author{
Daniel Goldman, ${ }^{*}$ Bruce M. Carlson, ${ }^{\dagger}$ and Julie Staple* \\ * Mental Health Research Institute \\ Department of Biological Chemistry \\ tDepartment of Anatomy and Cell Biology \\ The University of Michigan \\ Ann Arbor, Michigan 48109
}

\begin{abstract}
Summary
Expression of adult-type nicotinic acetylcholine receptors at the neuromuscular junction is thought to result from selective induction of their genes in endplateassociated nuclei due to local neurotrophic control. However, denervation studies indicate that endplatespecific expression can be maintained in the absence of the nerve. We investigated the role played by the basal lamina in this expression by assaying for the adult-typespecific $\varepsilon$ RNA in noninnervated regenerating muscle. We found that this RNA is locally expressed beneath the old endplates after $\mathbf{1 0}$ days of regeneration. At earlier times $\varepsilon$ RNA is also found in areas other than the endplate region. These results indicate that in adult muscle the basal lamina contains all the components necessary to direct nicotinic acetylcholine receptor gene expression to the endplate.
\end{abstract}

\section{Introduction}

During development of the neuromuscular junction (NM) there is a switch in the expression of nicotinic acetylcholine receptors ( $\mathrm{nAChR}$ ) from an embryonictype $\left(\alpha_{2} \beta \gamma \delta\right)$ to an adult-type $\left(\alpha_{2} \beta \varepsilon \delta\right)$ (Gu and Hall, 1988; Mishina et al., 1986; Witzemann et al., 1987, 1990). This switch in expression is correlated with muscle innervation. Embryonic receptors are found throughout the noninnervated muscle fibers' surface, whereas adult receptors are localized to the endplates of innervated fibers. This distribution of protein is reflected in the distribution of receptor RNA (Fontaine and Changeux, 1989; Goldman and Staple, 1989; Brenner et al., 1990). Loss of embryonic-type receptors from extrajunctional regions of the muscle fiber is a result of muscle activity suppressing expression of their genes (Goldman et al., 1988; Klarsfeld and Changeux, 1985). The mechanism by which adult-type nAChRs and their RNAs are locally expressed beneath the NMJ is not known. It may result from selective expression of nAChR genes in endplate-associated nuclei. Alternatively, all muscle nuclei might express adult-type nAChR genes, whose RNA is then transported to and/ or stabilized at the endplate.

The gene encoding the $\varepsilon$ subunit of adult-type receptors is unique in that it appears to be induced in endplate-associated nuclei as a result of muscle innervation (Brenner et al., 1990). However, unlike the other nAChR subunit-encoding genes, the $\varepsilon$ subunit gene is not regulated by muscle activity. In contrast, expression of the gene encoding the $\gamma$ suburit of embryonic receptors is suppressed by muscle activity and appears not to be induced at the NMJ (Goldman et al., 1988; Goldman and Staple, 1989). Therefore, the $\varepsilon$ RNA is an excellent marker for characterizing endplate-specific expression, while the $\gamma$ RNA is indicative of extrajunctional and activity-regulated expression.

Recently it has been shown that local induction of \& RNA expression beneath the NMJ requires muscle innervation. However, if one disrupts this interaction by denervation, $\varepsilon$ RNA persists at the endplate (Brenner et al., 1990). There are two possible explanations for this result: $\varepsilon$ RNA is extremely stable and remains at the endplate even after denervation, or brief interactions of nerve and muscle during development result in long-term changes at the NMJ. These changes persist in denervated muscle, resulting in endplatespecific expression of $\varepsilon$ RNA, even in the absence of the neuron. In the latter case we thought it likely that these interactions would be mediated through components of the synaptic basal lamina, as observed for nAChR clustering (Bader, 1981; MCMahan and Wallace, 1989). We tested these alternative possibilities by comparing the levels and distribution of $\varepsilon$ and $\gamma$ subunit-encoding RNA in regenerating noninnervated extensor digitorum longus (EDL) and soleus muscles. The regenerating muscle fibers result from fusion of dividing satellite cells that repopulate the original basal lamina. Therefore, these newly formed muscle fibers have never directly experienced the motoneuron.

Results

The methodology to produce noninnervated regenerating muscles is illustrated in Figure 1a and described in detail in Experimental Procedures. Briefly, muscles were denervated by sectioning the sciatic nerve high in the thigh. To induce muscle degeneration and regeneration, the denervated muscle was removed from the leg and soaked in a $0.75 \%$ Marcaine solution before grafting it back into its original site. The combination of Marcaine treatment and grafting results in elimination of over $99 \%$ of the original muscle fibers (Carlson, 1976). Therefore, all muscle fibers examined in the experiments reported below were regenerating and not innervated.

Induction of \& RNA Expression Beneath Old

Endplates of Noninnervated

Regenerating Muscle

In situ hybridization was used to assay for $\gamma$ and $\varepsilon$ RNA expression and distribution in noninnervated regenerating muscle. Probes used to identify these RNAs are illustrated in Figure 1b. The results of this type of 


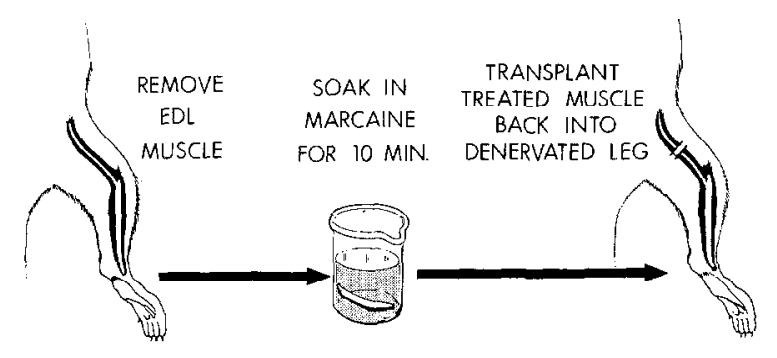

b

$\gamma, \varepsilon$ Genomic Structure

Extracellular $\quad$ M1 $\quad$ M2 $\quad$ M3 $\quad$ Cyto. MA M4

Protein Secondary Structure

$\gamma$-RNA probe

E-RNA probe

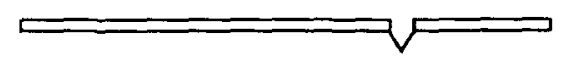

Figure 1. Schematic of Experimental Techniques Used to Study nAChR Gene Expression in Regenerating Muscles

(a) Generation of noninnervated regenerating muscle. See Experimental Procedures for details. Briefly, EDL or soleus muscles were excised, immersed in Marcaine, and sutured to the tendons of origin in its original bed.

(b) Probes used for in situ hybridization. The exon/intron organization of the $\gamma$ and $\varepsilon$ subunit-encoding genes based on studies of Buomanno et al. (1989). The lengths of the boxes (exons) and lines (introns) are not meant to reflect accurately the sizes of these introns and exons. The second line represents the protein domains encoded by these exons. $M 1$ through $M 4$ represent putative transmembrane domains, and MA represents an amphipathic helix that may interact with the membrane. The last two lines represent the sequences that the $\gamma$ and $\varepsilon$ RNA probes encompass.

analysis, performed on a day 20 noninnervated regenerating EDL muscle, are shown in Figure 2. Both $\gamma$ and $\varepsilon$ RNAs are expressed in these muscles. However, the distribution of these RNAs with in the fiber is very different. The $\gamma$ RNA is found throughout, whereas the $\varepsilon$ RNA is restricted to a small region of the fiber. Since these regenerating fibers were not innervated, one expects $\gamma$ RNA to be found throughout the fiber. The localized expression of the $\varepsilon^{\prime}$ RNA was surprising, since these regenerated myotubes were never innervated.

The simplest explanation for the local expression of $\varepsilon$ RNA in noninnervated regenerating muscle is that it results from selective expression of the $\varepsilon$ subunit gene in those myonuclei residing beneath the basal lamina that was part of the old NMJ. Alternatively, it is possible that all myonuclei express the $\varepsilon$ subunit gene, but its RNA is transported to and/or stabilized at the NMJ. In either case, $\varepsilon$ RNA would be concentrated beneath the basal lamina that was part of the old NMJ. This was tested by correlating our in situ hybridizations with acetylcholinesterase staining. Since acetylcholinesterase is attached to the synaptic basal lamina, one can identify basal lamina that was associated with the old synaptic region by staining for this enzyme. Following this staining, one can process the tissue for in situ hybridization to determine the relationship of synaptic basal lamina with that of $\varepsilon$ subunit gene expression. This analysis showed that $\varepsilon$ RNA was expressed beneath the synaptic basal lamina in day 14 noninnervated regenerating muscle fibers (Figure 3 ). Although the esterase-stained endplates obscure the 

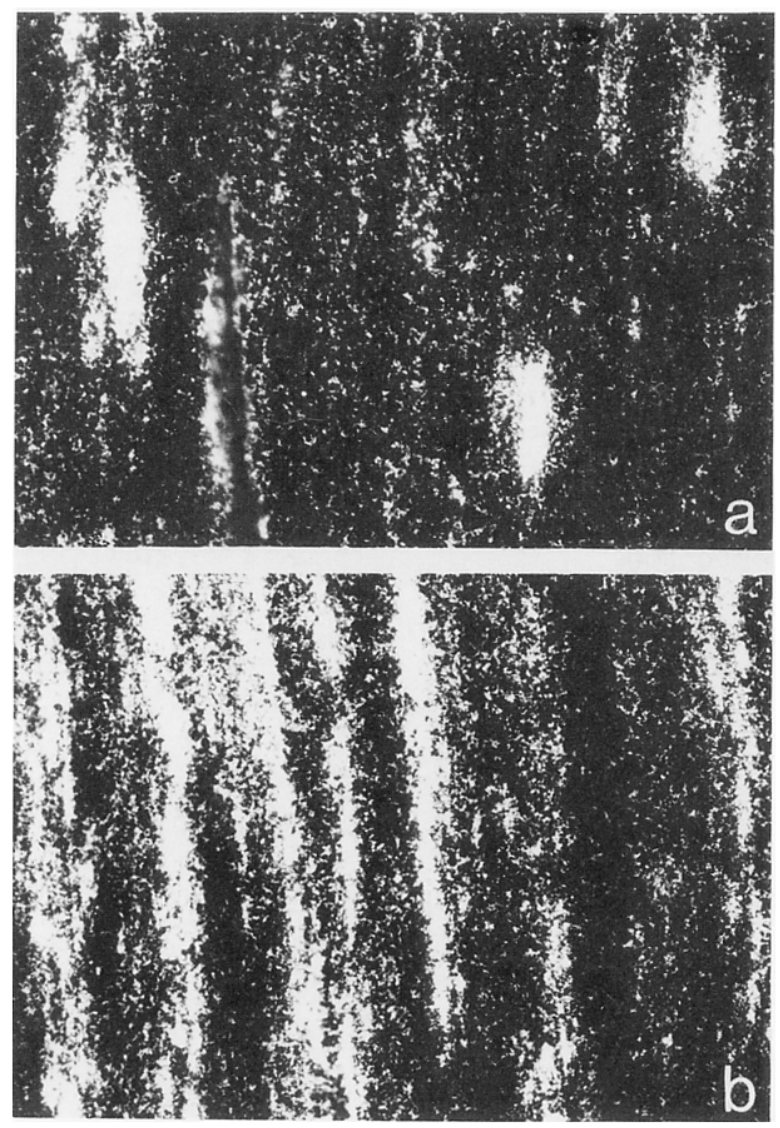

Figure 2. Distribution of $\varepsilon$ and $\gamma$ RNA in Day 20 Noninnervated Regenerating Muscle Fibers

In situ hybridization of longitudinal sections from day 20 noninnervated regenerating rat $\mathrm{EDL}$ muscle hybridized with antisense $\varepsilon$ (a) or $\gamma$ (b) RNA probes. The experimental paradigm along with in situ hybridization methods are described in Experimental Procedures. After in situ hybridization, all the slides were coated with liquid emulsion and exposed for 7 days. Photomicrographs were taken with a Zeiss Axiophot microscope equipped with dark-field optics and a $20 \times$ objective. Magnification, $37 \times$.

very high concentration of grains coincident with them, one can easily discern the steep gradient of grains around these endplates (for a correlation of high $\varepsilon$ RNA expression [grains] beneath endplates, see the serial sections of Figures $5 \mathrm{c}$ and $5 \mathrm{~d}$ ). One should remember that the stained endplates on muscle sections may represent only part of the endplate, and therefore the true extent of the full endplate may be underrepresented in these sections. These results indicate that components of the synaptic basal lamina direct $\varepsilon$ subunit gene expression to the endplate. However, these experiments have not eliminated the Schwann cell that caps the nerve terminals as contributing to this expression.

Temporal Expression of $\varepsilon$ RNA in Regenerating Muscle Reveals an Early Non-Endplate-Associated Pattern of Expression

The distribution and level of expression of $\gamma$ and $\varepsilon$
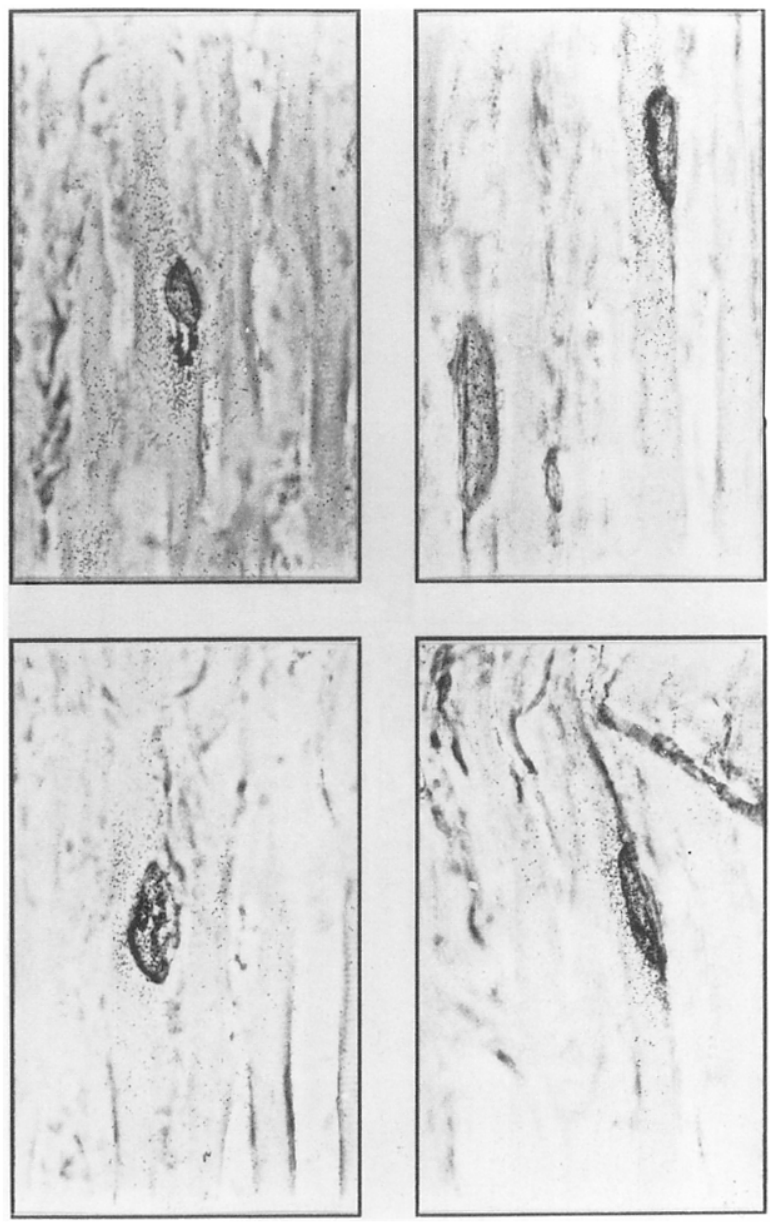

Figure 3. Localization of $\varepsilon$ RNA Beneath Synaptic Basal Lamina in Noninnervated Regenerating EDL Muscle

Longitudinal sections of day 14 noninnervated regenerating EDL muscle were stained for acetylcholinesterase as previously described by Koelle and Friedenwald (1949). Sections were then processed for in situ hybridizations. The histochemical stain for acetylcholinesterase survived the in situ hybridization protocol, allowing endplates and $\varepsilon$ RNA to be identified on the same section. Four different representative sections are shown with grains, representing \& RNA, clustered near stained endplates. Pictures were taken using bright-field optics and a $40 \times$ objective of a Zeiss Axiophot microscope. Magnification, $62 \times$. Exposure times for in situ hybridizations were generally 2 weeks; those for sections not stained for acetylcholinesterase were 1 week.

subunit-encoding RNAs was compared at 2, 4,7, 10, 15,20 , and 35 days following the experimental surgery (Figure 4). At 2 days, no nAChR RNA could be detected. This result is not surprising, since most of the original fibers had undergone considerable intrinsic degeneration and muscle regeneration was only at the stage of satellite cell activation. We have not been able to detect $\varepsilon$ or $\gamma$ RNA reliably in dividing satellite cells. Within the next 2 days, myotubes began to form and express both the $\gamma$ and the $\varepsilon$ genes. The level of expression of these genes and the distribution of their RNAs within the regenerating fibers were very similar at this time point. However, both $\gamma$ and $\varepsilon$ RNA expression 


\section{Denervated/Regenerating Muscle}

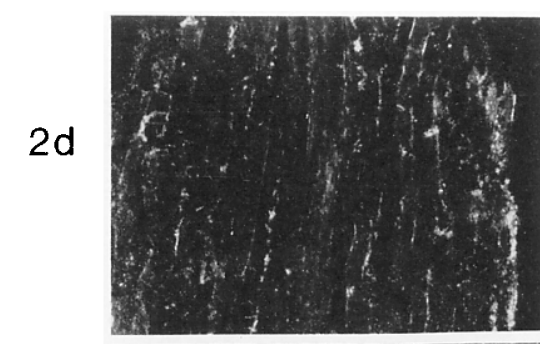

$4 d$

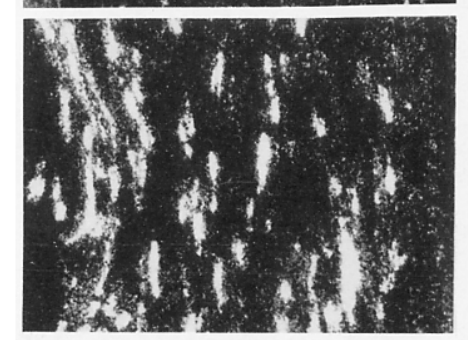

$7 d$

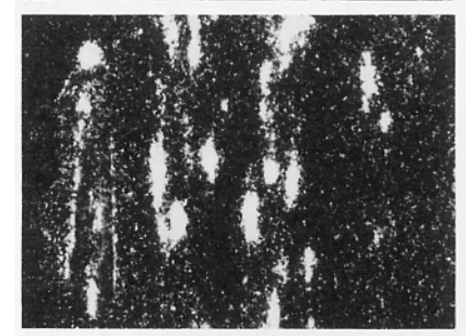

$20 d$

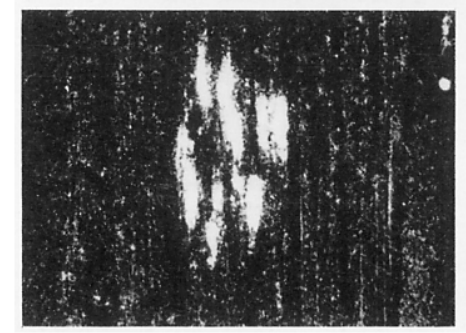

EPSILON
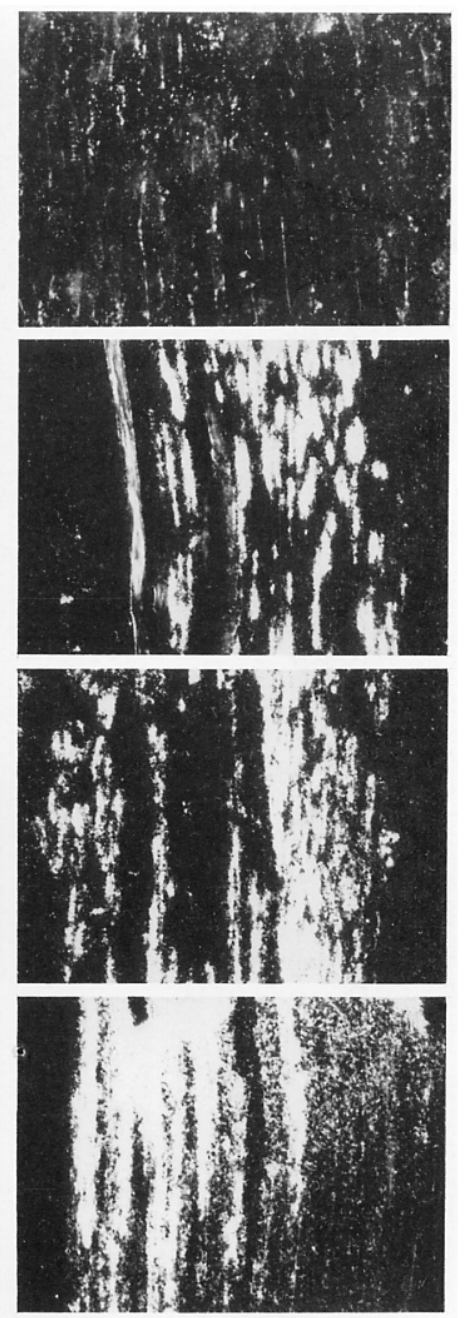

Figure 4. Spatial and Temporal Comparison of $\varepsilon$ and $\gamma$ RNA Expression in Noninnervated Regenerating EDL Muscles

In situ hybridization of longitudinal sections from $2,4,7$, and 20 day noninnervated regenerating EDL. muscle with antisense $\varepsilon$ or $\gamma$ RNA-specific probes. After in situ hybridization, slides were exposed to emulsion for 7 days. Photomicrographs were taken using dark-fjeld optics and $\mathrm{a} 10 \times \mathrm{ob}$ jective. Magnification, $16 \times$. was heterogeneous among the myotubes with most expressing these RNAs at relatively high levels, and some expressing them at moderate to low levels. Although the regenerating fibers were quite small, the $\gamma$ and $\varepsilon$ RNAs appeared to be found throughout them. This expression was generally found at the extreme distal and proximal ends of the muscle, where regeneration was most easily observed. Surprisingly, these regions were devoid of endplates, as revealed by acetylcholinesterase staining (see Figure 5). Any differences noticed between $\varepsilon$ and $\gamma$ RNA expression around day 4 of regeneration could be attributed to variability in the number and length of regenerating myotubes in the different muscle sections.

The first clear difference in the distribution of these RNAs was observed at day 7 , when the $\varepsilon$ RNA showed a much more restricted pattern of expression compared with the $\gamma$ RNA. Acetylcholinesterase staining of serial sections revealed that some of the patches of $\varepsilon$ RNA resided beneath the old NMJs (data not shown). By day 20 of regeneration the muscle fibers appeared similar to normal adult fibers, with $\varepsilon$ RNA localized to a discrete region of the fiber, corresponding to old NMJs (Figure 3), and $\gamma$ RNA more diffusely distributed throughout.

\section{$\varepsilon$ RNA Expression Is Independent of Old Endplates during the Initial Stages of Regeneration}

The reason $\varepsilon$ RNA was initially found throughout the regenerating myofiber (day 4) prior to becoming localized to a discrete region (day 14) is not known. One possibility, based on the observation that myoblasts can migrate longitudinally (Schultz et al., 1985) and cross basal lamina boundaries in developing muscle (Hughes and Blau, 1990), is that myoblasts which experienced the old endplate were able to migrate into 
(+) Endplates

Day 4

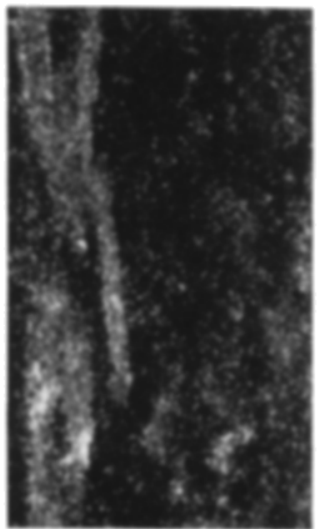

a

Day 14

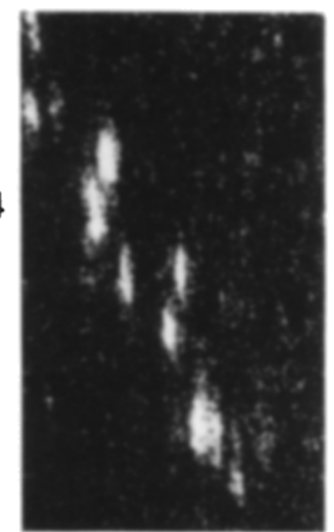

C

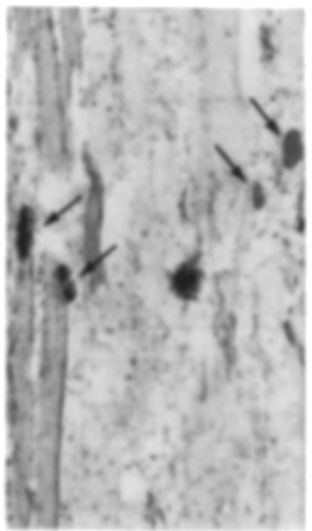

b

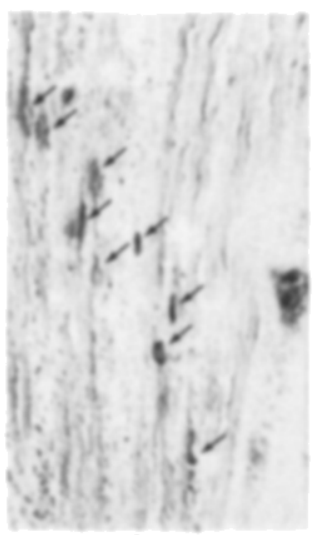

d
(-) Endplates

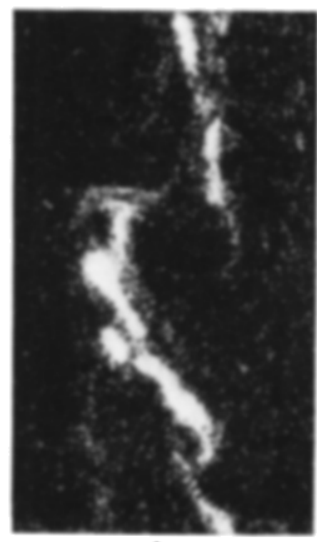

$\mathbf{e}$

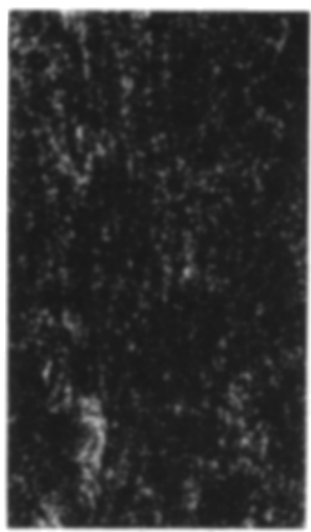

g
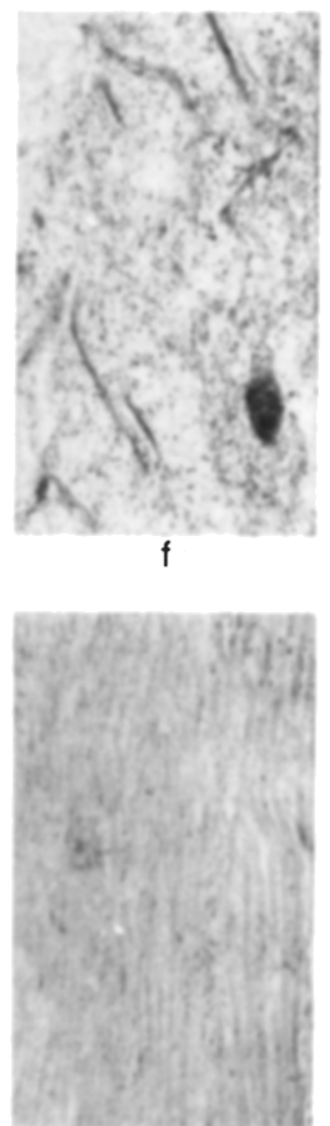

h

Figure 5. Comparison of $\varepsilon$ RNA Expression in Noninnervated Regenerating Muscle Containing or Lacking Endplates

Soleus muscles were denervated and induced to regenerate. In one set of soleus muscles ((-) Endplates) we first cut out the middle, endplate-enriched third of the muscle and ligated the extrajunctional outer two-thirds together. These muscles were allowed to regenerate. At days 4 and 14 of regeneration, muscles were isolated and sectioned. Serial sections were prepared for in situ hybridization and acetylcholinesterase staining. Each pair of pictures represents a dark-field photomicrograph showing $\varepsilon$ RNA expression and a serial section showing a bright-field photomicrograph of acetylcholinesterase-stained endplates (arrows). Magnification, 19x. (a) and (b) shows a central region of the soleus muscle containing endplates but lacking $E$ RNA. This lack of expression reflects the presence of ischemic fibers in this region of the muscle. Although not shown, $\varepsilon$ RNA expression could be seen at the distal or proximal ends of this muscle as seen in (e) and $(f)$. The photo of the same time point in the endplate-lacking muscle (e and $f$ ) was taken at the end of the muscle, where $\varepsilon$ RNA expression is most easily observed; however, no endplates can be detected. At day 14 of regeneration, one finds $\varepsilon$ RNA colocalizing to endplate regions of the endplate containing muscle ( $c$ and d), whereas no expression is found in the endplate-lacking muscle (random central region shown in [g] and [h]).

non-endplate regions. This may give rise to a transient pattern of $\varepsilon$ subunit gene expression in non-endplate regions of the regenerating fiber.

One can test this idea by comparing the pattern of $\varepsilon$ subunit gene expression in regenerating muscle containing or lacking endplates. We accomplished this by inducing soleus muscles to regenerate as described for the EDI muscle. However, to generate muscle lacking endplates, the middle (endplate enriched) third of the muscle was excised and the extrajunctional portions were ligated together. Muscles were returned to their original bed, and 4 and 14 days later they were assayed for $\gamma$ and $\varepsilon$ subunit gene expression. Serial sections were stained for acetylcholinesterase to identify endplates. These experiments showed similar levels and distribution of s. subunit gene expression in endplate-containing and lacking regenerates at day 4 . The expression was found predominantly in the distal and proximal regions of the muscle, where regeneration was most easily observed. No expression could be found in the central region of the soleus muscle, where endplates normally reside. This lack of expression reflects the preponderance of ischemic fibers and a lack of regenerating fibers in this region of the muscle at this early time of regeneration. Figures $5 a$ and $5 b$ show that at day 4 $\varepsilon$ RNA is not detected in the central region of an endplate-containing regenerate (identical results were obtained with an endplate-lacking regenerate). However, $\varepsilon$ RNA is detected at either the distal or the 
a

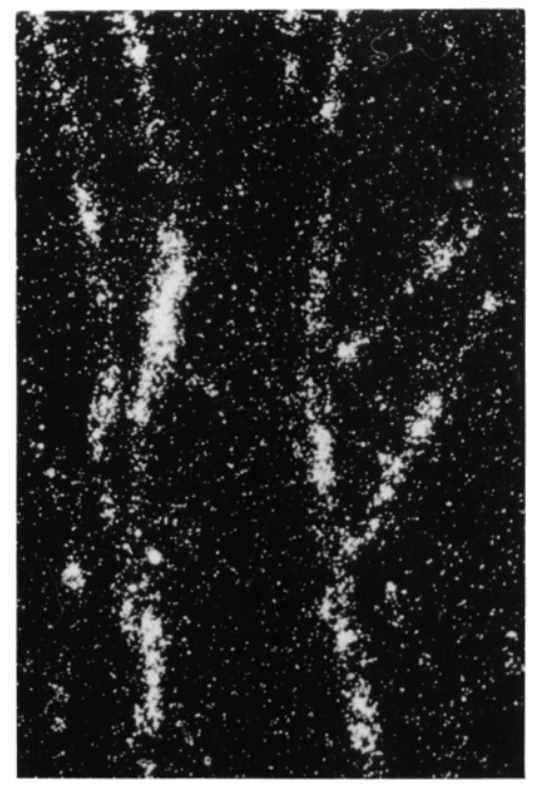

b

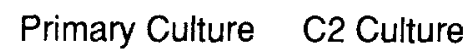

D

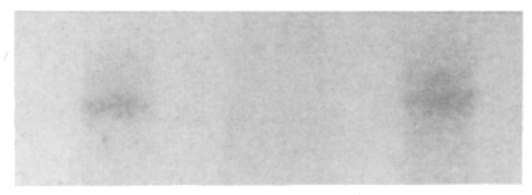

C

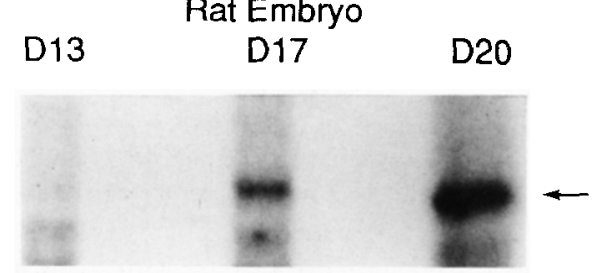

Figure 6. Expression of $\varepsilon$ RNA in Noninnervated Cultured Muscle Cells and Embryonic Tissue

(a) In situ hybridization of differentiated rat primary muscle cells in culture with antisense $\varepsilon$ RNA probe. Myotubes were maintained in cultu re for 2 weeks prior to processing for in situ hybridization. This dark-field photomicrograph was taken with a $20 \times$ objective. Magnification, 41×. Hybridized muscles were exposed to emulsion for 1 week.

(b) RNAase protection assay confirming $\varepsilon$ RNA expression in cultured muscle cells. Approximately $20 \mu \mathrm{g}$ of total RNA was used in each of these protections. Lane D, RNA isolated from differentiated myotubes maintained for 1 week in culture; lane U, RNA isolated from undifferentiated myoblasts. Autoradiograms were exposed to X-ray film overnight.

(c) RNAase protection assay showing $\varepsilon$ RNA expression in day 17 (D17) and day 20 (D20) rat embryos.

The arrow points to the fragment of $\varepsilon$ RNA specifically protected by the antisense probe. The fainter band below this is generated artifactually from the probe, since appearance is independent of addition of muscle RNA in the RNAase protection assay. Approximately $38 \mu \mathrm{g}$ of total RNA was used in each protection. D13 is RNA isolated from day 13 embryonic bodies lacking heads; D17 proximal regions of endplate-containing or -lacking muscle, (data for endplate-lacking regenerate are shown in Figures $5 \mathrm{e}$ and $5 \mathrm{f}$ ). By day 14 normal regenerating muscle showed the typical localization of $\varepsilon$ RNA to the endplate-containing central region (Figures $5 \mathrm{C}$ and $5 \mathrm{~d}$ ), whereas regenerating soleus muscle lacking endplates showed no $\varepsilon$ RNA expression (Figures $5 g$ and $5 h$ show a central region of the endplate-lacking muscle). Therefore, unlike the localized expression of $\varepsilon$ RNA in day 14 regenerates, the early pattern of $\varepsilon$ subunit gene expression does not appear to depend upon the presence of the original endplates.

\section{$\varepsilon$ RNA Is Expressed in the Noninnervated Mouse C2} Cell Line and Rat Primary Muscle Cultures

Since $\varepsilon$ RNA is expressed early during muscle regeneration in non-endplate regions of the muscle, we examined whether this gene is also expressed in noninnervated muscle cells in culture. Rat primary muscle cells were isolated from day 18-20 embryos and grown in culture. In situ hybridization shows that $\varepsilon$ RNA is expressed throughout the myotubes of rat primary muscle cultures (Figure 6a). This pattern of expression, as assayed by in situ hybridization, did not change significantly between myotubes maintained in culture for 3 days versus 2 weeks. This expression was confirmed by RNAase protection assays (Figure 6b). No expression was detected in undifferentiated myoblasts, whereas significant expression was found in differentiated myotubes derived from rat primary myoblasts and the continuous mouse muscle cell line, $\mathrm{C} 2$.

The finding of $\varepsilon$ RNA expression in rat primary muscle cells grown in culture prompted us to look for its expression during embryonic development. For this analysis we used the more sensitive RNAase protection assay. This assay revealed low to undetectable levels of $\varepsilon$ RNA in day 13 embryos, yet by day 17 significant levels of this transcript were detected (Figure 6c). Since the day 13 RNA was isolated from embryonic bodies and the day 17 and day 20 RNAs were isolated from embryonic limbs, it is difficult to make quantitative conclusions about the abundance of this transcript during embryonic development.

\section{Discussion}

The experiments reported here were designed to test the role the basal lamina played in maintaining $n A C h R$ RNA expression at the endplates of denervated adult skeletal muscle. Our strategy was to denervate the muscle and then induce rapid degeneration followed by regeneration by using a combination of Marcaine treatment and grafting. Marcaine is a local anesthetic drug that induces rapid degeneration and regeneration of whole skeletal muscle (Benoit and Belt, 1970). Grafting causes the destruction of a large central core

and $\mathrm{D} 20$ are RNAs isolated from limbs. Autoradiograms were exposed to X-ray film for 2 days. 
of muscle fibers due to ischemic necrosis, but leaves a thin rim of surviving muscle fibers at the periphery of the graft. Soaking the removed muscle in Marcaine results in the destruction of almost all of the remaining peripheral muscle fibers in the graft (Carlson, 1976). Following this procedure the muscle fibers underwent first ischemic, and then phagocyte-mediated degeneration. Then, in conjunction with spontaneous revascularization, new muscle fibers regenerated within the persisting basal laminae from the original muscle fibers. Reinnervation of muscle was prevented by using a denervation procedure that included, in addition to sectioning the sciatic nerve, suturing the proximal and distal nerve stumps and implanting the proximal nerve stump into a nearby muscle. Previous experiments, employing silver staining of segments of the distal nerve and electrical stimulation of the transected sciatic nerve have shown that this denervation procedure prevents the return of nerve fibers for a period of time extending beyond 22 months (Carlson and Faulkner, 1988). Therefore, the newly formed fibers have never directly experienced the motoneuron.

After approximately 14 days of regeneration, $\varepsilon$ RNA was found localized beneath the old endplates, whereas $\gamma$ RNA was found throughout the fiber (Figures $2,3,4$, and 5). These results are consistent with the idea that the basal lamina can maintain endplatespecific expression of $\varepsilon$ RNA in the absence of the innervating neuron. It is unlikely that this localized expression of $\varepsilon$ RNA resulted from reinnervation of regenerating muscle fibers for the following reasons: the denervation procedure allows permanent denervation of the lower leg (Carlson and Faulkner, 1988); serial sections showed high levels of $\gamma$ RNA throughout the muscle fiber, which would be low to undetectable if the muscles were reinnervated; and the majority of identified endplates expressed $\varepsilon$ RNA locally beneath them (a minority would be expected if a few fibers were able to be reinnervated). In addition, this expression was not due to surviving original muscle fibers, since at early times of regeneration (day 2) no fibers expressing $\varepsilon$ or $\gamma$ RNA could be identified and all expression at later times was confined to the rather thin, easily identifiable regenerating fibers (Figure 4). The lack of surviving original muscle fibers is consistent with previous reports showing over $99 \%$ of the original muscle fibers are eliminated by a combination of Marcaine treatment and grafting (Carlson, 1976).

The information mediating this local expression appears to reside in the basal lamina. The components of the basal lamina participating in this effect may be either derived from the motoneuron or induced in muscle upon innervation. In either case, deposition in the basal lamina would occur. Since the effects of the basal lamina persist for long periods of time following denervation, it is likely that the responsible component is quite stable. Alternatively, this component may be autoregulatory so that its presence in the basal lamina induces its synthesis in the muscle. This activity of the basal lamina explains the imprinting noticed by other investigaturs in which $\mathrm{s}$ subunit gene expression is initiated by muscle innervation, but its maintenance does not depend upon continued innervation (Brenner et al., 1990). In this case the basal lamina serves as a type of memory for the muscle, conferring nerve-dependent properties on a noninnervated fiber. These results indicate the importance of basal lamina components in defining and maintaining synaptic and extrasynaptic domains of the muscle fiber.

The components of the basal lamina responsible for inducing adult-type $n A C h R$ gene expression are not known. However, candidates include extracellular matrix molecules localized to the endplate, such as agrin, and perhaps receptors for calcitonin gene-related peptide, ARIA, or ascorbate (McMahan and Wallace, 1989; Usterlund et al., 1989; Harris et al., 1988; Horovitz et al., 1989). These latter receptors are not likely to be directly responsible for the local induction of $\varepsilon$ RNA at the old endplates of regenerating muscle, since these muscles were not innervated and therefore these receptors would be deprived of their neurally derived ligands. However, basal lamina components that are expressed locally upon muscle innervation, but function independent of the neuron, are likely candidates for mediating the endplate-specific expression of $\varepsilon$ RNA. ARIA, which is a $42 \mathrm{kd}$ glycoprotein purified from chick brains, may be such a molecule. It induces synthesis of nAChRs (Harris et al., 1988); however; whether it resides in the synaptic basal lamina is not known. Agrin is a component of synaptic basal lamina that induces $\mathrm{ACC}$ Ch clustering; however, agrin has been reported to have no effect on $n A C h R$ synthesis (McMahan and Wallace, 1989).

Unlike the localized pattern of $\varepsilon$ RNA expression after a couple weeks of regeneration, at early times (day 4) $\varepsilon$ RNA, like $\gamma$ RNA, is found in non-endplate regions of the fiber (Figure 5). This is exemplified by the observation that $\varepsilon$ RNA expression is most prevalent at the proximal and distal ends of the regenerating muscle that lack endplates. In addition, if one assays for $\varepsilon$ RNA at endplate-enriched regions, litile or no \& RNA expression can be detected (Figure 5). This latter observation does not necessarily imply that $\varepsilon$ RNA expression is repressed beneath the old endplates, but rather reflects a derth of regenerating fibers associated with old endplates at this early time point. Therefore the pattern of $\varepsilon$ RNA distribution observed at this early time of regeneration reflects the distribution of regenerating and ischemic fibers. The proximal and distal ends of the muscle are enriched for regenerating fibers, whereas the central portion is enriched for ischemic fibers.

Since the day 4 regenerating muscle indicated that $\varepsilon$ RNA expression could be induced prior to innervation in extrajunctional regions of the muscle fiber, we investigated whether this gene was also expressed in noninnervated muscle cells in culture. In situ hybrid- 
izations and RNAase protection assays showed that the continuous mouse muscle cell line, $\mathrm{C} 2$, and rat primary muscle cells in culture express $\varepsilon$ RNA upon differentiation (Figure 6). In addition, this RNA was found throughout the myotube (Figure 6a). These results are consistent with those of Martinou and Merlie (1991), who recently reported $\varepsilon$ RNA expression in a number of different noninnervated muscle cell lines. In addition, these results are consistent with electrophysiological studies showing two classes of nAChR channels expressed in rat primary muscle cultures (Siegelbaum et al., 1984). Therefore, this early expression of $\varepsilon$ RNA in regenerating muscle and in noninnervated embryonic muscle may be a result of an endogenous myogenic program (Martinou and Merlie, 1991).

One difference between the day 4 regenerating muscle and muscle cells in culture is the abundance of $\varepsilon$ RNA relative to $\gamma$ RNA. In day 4 regenerating muscle the levels of these two RNAs were similar (Figure 4), yet in muscle cell cultures the level of $\varepsilon$ RNA was approximately 20-fold lower than $\gamma$ RNA (Martinou and Merlie, 1991; Goldman unpublished data). The significance of this difference is not known, but may represent inherent differences in the myogenic program of myoblasts versus satellite cells or the differentiation of these cells in the presence (satellite cells) or the absence (cultured muscle cells) of an adult basal lamina.

In conclusion, we have shown that $\varepsilon$ RNA expression in noninnervated regenerating muscle is regulated by two sequential mechanisms. First, at early times of regeneration $\varepsilon$ RN $\wedge$ is expressed throughout the myotube, perhaps as a result of an endogenous myogenic program, which also may explain the low level of $\varepsilon$ RNA expression found in noninnervated myotubes in culture. Second, as the muscle matures, $\varepsilon$ RNA expression disappears from extrajunctional regions and becomes localized to the endplate. This latter expression may result from components of the adult basal lamina suppressing extrajunctional $\varepsilon$ RNA expression and/or inducing it at the endplate. The possibility that the adult basal lamina causes a reorganization of $\varepsilon$ gene-expressing nuclei from nonendplate to endplate regions seems unlikely for two reasons: the number of nuclei initially contributing to non-endplate expression far exceeds the number of endplate nuclei contributing to this expression in older regenerating muscle. $\Lambda$ simple redistribution of nuclei would imply that the same number would be associated with nonendplate and endplate regions; and when endplates were removed from the soleus muscle prior to regeneration and the muscle was allowed to regenerate, we found that $\varepsilon$ RNA expression disappeared by day 14 (Figure 5). These latter data support the idea of an endugenous program regulating non-endplate $\varepsilon$ RNA expression and not the repositioning of nuclei within the regenerating myotube. The final possibility that all nuclei of the adult muscle fiber express $\varepsilon$ RNA and it is transported or stabilized at the endplate does not seem likely in light of recent experiments showing that transgenic animals are able to use the $\alpha$ subunit gene promoter to confer endplate-specific expression on the reporter gene $\beta$-galactosidase (Klarsfeld et al., 1991). Since this RNA is different from those encoding the nAChRs, one would not expect it to be transported or stabilized in a fashion similar to that of the nAChR RNAs. The fact that the $\beta$-galactosidase protein was transiently detected in endplate-associated nuclei from postnatal day 1 through day 4 in the transgenic mouse probably reflects peak expression of this enzyme during this developmental period, which falls below detectable limits at later times. This is consistent with the peak in $\varepsilon$ subunit RNA expression found to occur in the rat during the first 2 weeks following birth (Witzemann et al., 1989). The finding that the nAChR $\alpha$ subunit promoter confers endplate-specific expression on both $\beta$-galactosidase- and $\alpha$ subunit-encoding RNAs argues for a transcriptional mechanism controlling the spatial expression of this gene in muscle.

\section{Experimental Procedures}

Generation of Noninnervated Regenerating Muscle

The experiment was conducted on 6-month-old male Wistar rats of the F-455 strain maintained at the University of Michigan. Rats were anesthetized with ether. The right legs of the rats were first denervated by sectioning the sciatic nerve high in the thigh, suturing the proximal and distal stumps, and implanting the proximal stump into a hip muscle. This procedure allows a permanent denervation of the lower leg (Carlson and Faulkner, 1988). At the same time, the right soleus or EDL muscle was removed from the leg, soaked for $10 \mathrm{~min}$ in $0.75 \%$ Marcaine (Winthrop Breon Inc.), and then freely grafted back into its original site. The combination of free grafting plus Marcaine treat ment ensures elimination of over $99 \%$ of the original muscle fibers (Carlson, 1976). Free grafting, causes the destruction of a large central core of muscle fibers due to ischemic necrosis, but leaves a thin rim of surviving muscle fibers at the periphery of the graft. Soaking the removed muscle in Marcaine, a highly myotoxic anesthetic, results in the destruction of almost all of the remaining peripheral muscle fibers in the graft. The grafting operation involved suturing the proximal and distal ends of the muscle to the tendon stumps in the leg. No attempt was made to restore the vascular supply. Following the grafting procedure, the muscle fibers underwent first ischemic and then phagocyte mediated degeneration. Then, in conjunction with spontaneous revascularization, new muscle fibers regenerated within the persisting basal laminae from the original muscle fibers. At various times from 2 to 35 days following surgery, the rats were perfused with $4 \%$ paraformaldehyde-PBS, and the regenerating plus contralateral control muscles were removed and processed for in situ hybridization.

\section{Probes and In Situ Hybridization}

Two probes were used in these studies. The $\gamma$ subunit cDNA has already been described (Cioldman and Staple, 1989). The rat $\varepsilon$ subunit-encoding CDNA (19-1-1) was isolated from a denervated rat skeletal muscle cDNA library, using a mouse $\varepsilon$ subunitencoding CDNA or genomic DNA fragment as a probe (kindly provided by Dr. Gardner, Dartmouth and Dr. Merlie, Washington University). DNA sequence analysis showed this clone to cover nucleotides 575-1612 of the published rat clone (Criado et al., 1988). In addition, RNAase protection assays indicated that this clone contained an intron at position 1257. This was confirmed by $D N A$ sequencing. Inspection of the $\varepsilon$ gene sequence shows that this intron is situated between exons 10 and 11 (Buonanno et al., 1989). ${ }^{35}$ S-labeled sense and antisense RNA probes were generated from linearized vectors by run-off transcription 
(Meiton et al., 1984) using [35S]uridine $5^{\prime}$-( $\alpha$-thio)triphosphate (40 $\mathrm{mCi} / \mathrm{ml}$; Amersham) and either SP6 or 17 polymerase (Promega) Probes were labeled to appoximately the same specific activity and used at a concentration of $50,000 \mathrm{cpm}$ per $\mu$ l of hybridization solution. The in situ hybridization procedure has previously been described (Goldman and Staple, 1989). For primary muscle cultures we decreased the proteinase $\mathrm{K}$ digestion time to $7 \mathrm{~min}$. In situ hybridizations with regenerating muscle sections were repeated a minimum of 3 times with different animals. All repetitions yielded similar results. Sense-strand probes consistently gave background signals.

\section{RNA Isolation and RNAase Protection Assay}

RNA was isolated from muscle cell cultures and embryonic tissuc using the guanidinium isothiocyanate procedure as previously described (Chirgwin et al., 1979; Goldman et al., 1985). Embryos were dissected from time-mated pregnant Spraque-Dawley rats (Charles River). RNAase protection assays were carried out as previously described (Goldman and Staple, 1989). An antisense ${ }^{32}$ P-labeled $\varepsilon$ RNA probe was prepared from the same vector (19-1-1) as described above. Linearization of clone 19-1-1 with BamHI, which cleaves this DNA in exon 10, results in approximately a $0.5 \mathrm{~kb}$ probe that will protect two fragments in the RNAase protection assay. One fragment (approximately $355 \mathrm{nu}-$ cleotides) is the result of protecting exons 11 and 12; the other fragment (approximately 140 nucleotides) results from protection of the remaining exon 10 sequences. The data presented in this paper show only the larger fragment.

\section{Primary and Clonal Cell Cultures}

Day $18-20$ rat embryos were used to isolate myoblasts for primary muscle cultures. Hind legs including thigh were deskinned, and the thigh muscles were removed into PBS. Muscles were tweezed apart and placed into $0.25 \%$ trypsin, PBS at $37^{\circ} \mathrm{C}$ for approximately 20-30 min with frequent trituration. Cells were centrifuged and resuspended in DMEM and filtered through a 20 mesh screen. The cells were pelleted again and resuspended in DMEM, $10 \%$ fetal calf serum and plated on collagen-coated coverslips at a density of $4 \times 10^{5}$ cells per 35 -mm culture dish. After about 4 days in culture, myotubes had begun to form and within the next few days began to contract spontaneously. Growth of the clonal $\mathrm{C} 2$ cell line was as previously described (Evans et al., 1987).

\section{Acknowledgments}

This work was supported by grants from the National Institutes of Health (D. G. and B. M. C.), the Muscular Dystrophy Association (D. G.), and the Lucille B. Markey Charitable Trust (D. G.).

The costs of publication of this article were defrayed in part by the payment of page charges. This article must therefore be hereby marked "advertisement" in accordance with 18 USC Section 1734 solely to indicate this fact.

Received March 14, 1991; revised July 9, 1991.

\section{References}

Bader, D. (1981). Density and distribution of a-bungarotoxinbinding sites in postsynaptic structures of regenerated rat skeletal muscle. I. Cell Biol. 88, 338-345.

Benoit, P. W., and Belt, D. W. (1970). Destruction and regeneration of skeletal muscle after treatment with a local anaesthetic, bupivacaine (Marcaine). J. Anat. 107, 547-556.

Brenner, H. R., Witzemann, V., and Sakmann, B. (1990). Imprinting of acetylcholine receptor messenger RNA accumulation in mammalian neuromuscular synapses. Nature 344, 544-547.

Buonanno, A., Mudd, J., and Merlie, J. P. (1989). Isolation and characterization of the $\beta$ and $\varepsilon$ subunit genes of mouse muscle acetylcholine receptor. J. Biol. Chem. 264, 7611-7616.

Carlson, B. M. (1976). A quantitative study of muscle fiber survival and regeneration in normal, predenervated, and Marcainetreated free muscle grafts in the rat. Exp. Neurol. 52, 421-432.
Carlson, B. M., and Faulkner, J. A. (1988). Reinnervation of longterm denervated rat muscle freely grafted into an innervated limb. Exp. Neurol. 102, 50-56.

Chirgwin, J. M., Przybyla, A. E., MacDonald, R. J., and Rutter, W. J. (1979). Isolation of biologically active ribonucleic acid from sources enriched in ribonuclease. Biochemistry 18, 5294-5299.

Criado, M., Witzemann, V., Koenen, M., and Sakmann, B. (1988). Nucleotide sequence of the rat muscle acetylcholine receptor $\varepsilon$ subunit. Nucl. Acids Res. 16, 10920.

Evans, S., Goldman, D., Heinemann, S., and Patrick, J. (1987). Muscle acetylcholine receptor biosynthesis. ). Biol. Chem. 262, 4911-4916.

Fontaine, B., and Changeux, J.P. (1989). Localization of nicotinic acetylcholine receptor $\alpha$ subunit transcripts during myogenesis and motor endplate development in the chick. J. Cell Biol. 108, 1025-1037.

Goldman, D., and Staple, J. (1989). Spatial and temporal expression of acetylcholine receptor RNAs in innervated and denervated rat soleus muscle. Neuron 3, 219-228.

Goldman, D., Boulter, J., Heinemann, S., and Patrick, J. (1985). Muscle denervation increases the levels of two miRNAs coding for the acetylcholine receptor $\alpha$ subunit. J. Neurosci. 5, 25532558.

Goldman, D., Brenner, H. R., and Heinemann, S. (1988). Acetylcholine receptor $\alpha-, \beta-, \gamma-$, and $\delta$-subunit mRNA levels are regulated by muscle activity. Neurnn 1, 329-333.

Gu, Y., and Hall, Z. W. (1988). Immunological evidence for a change in subunits of the acetylcholine receptor in developing and denervated rat muscle. Neuron 1, 117-125.

Harris, D. A., Falls, D. L., Dill-Devor, R. M., and Fischbach, G. D. (1988). Acetylcholine receptor-inducing factor from chicken brain increases the level of mRNA encoding the receptor a subunit. Proc. Natl. Acad. Sci. USA 85, 1983-1987.

Horovitz, O., Knaack, D., Podleski, T. R., and Salpeter, M. M. (1989). Acetylcholine receptor $\alpha$ subunit mRNA is increased by ascorbic acid in cloned $L 5$ muscle cells: Northern blot analysis and in situ hybridization. J. Cell Biol. 108, 1823-1832.

Hughes, S. M. and Blau, H. M. (1990). Migration of myoblasts across basal lamina during skeletal muscle development. Nature 345, 350-353.

Klarsfeld, A., and Changeux, J.-P. (1985). Activity regulates the levels of acetylcholine receptor $\alpha$ subunit mRNA in cultured chicken myotubes. Proc. Natl. Acad. Sci. USA 82, 4558-4562.

Klarsfeld, A., Bessereau, J. L., Salmon, A. M., Triller, A., Babinet, C., and Changeux, J.P. (1991). An acetylcholine receptor $\alpha$ subunit promoter conferring preferential synaptic expression in muscle of transgenic mice. EMBO J. 10, 625-632.

Koelle, G. B., and Friedenwald, J. S. (1949). A histochemical method for localizing cholinesterase activity. Proc. Soc. Exp. Biol. Med. 70, 617-622.

Martinou, J. C., and Merlie, J.P. (1991). Nerve-dependent modulation of acetylcholine receptor $\varepsilon$ subunit gene expression. I. Neurosci. 11, 1291-1299.

McMahan, U. J., and Wallace, B. G. (1989). Molecules in basal lamina that direct the formation of synaptic specializations at neuromuscular junctions. Dev. Neurosci. 11, 227-247.

Melton, D. A., Krieg, P. A., Rebagliati, M. R., Maniatis, T., Zinn, K., and Green, M. R. (1984). Efficient in vitro synthesis of biologically active RNA and RNA hybridization probes from plasmids containing a bacteriophage SPG promoter. Nucl. Acids Res. 12, 70357056 .

Mishina, M., Takai, T., Imoto, K., Noda, M., Takahashi, T., Numa, S., Methfessel, C., and Sakmann, B. (1986). Molecular distinction between fetal and adult forms of muscle acetylcholine receptor. Nature 321, 406-411.

Osterlund, M., Fontaine, B., Devillers-Thiery, A., Geoffroy, B. and Changeux, J.-P. (1989). Acetylcholine receptor expression in primary cultures of embryonic chick myotubes. Neuroscience $32,279-287$. 
Schultz, E., Jyraszak, D. L., and Valliere, C. R. (1985). Response of satellite cells to focal skeletal muscle injury. Muscle Nerve 8 , 217-222.

Siegelbaum, S. A., Trautmann, A., and Koenig, J. (1984). Single acetylcholine-activated channel currents in developing muscle cells. Dev. Biol. 104, 366-379.

Witzemann, V., Barg, B., Nishikawa, Y., Sakmann, B., and Numa, S. (1987). Differential regulation of muscle acetylcholine receptor $\gamma$ and $\varepsilon$ subunit mRNAs. FEBS Lett. 223, 104-112.

Witzemann, V., Barg, B., Criado, M., Stein, E., and Sakmann, B. (1989). Developmental regulation of five subunit specific mRNAs encoding acetylcholine receptor subtypes in rat muscle. FEBS Lett. 242, 419-424.

Witzemann, V., Stein, E., Barg, B., Konno, T., Koenen, M., Kues, W., Criado, M., Hofmann, M., and Sakmann, B. (1990). Primary structure and functional expression of the $\alpha-, \beta-, \gamma-, \delta$ - and $\varepsilon$-subunits of the acetylcholine receptor from rat muscle. Eur. J. Biochem. 194, 437-448. 